\title{
Risk Factors for a Complicated Clinical Course Among Women Hospitalized With Pelvic Inflammatory Disease
}

\author{
Denise J. Jamieson, ${ }^{1,2} *$ Ann Duerr, ${ }^{2}$ Milagros A. Macasaet, ${ }^{3}$ \\ Herbert B. Peterson, ${ }^{2}$ and Susan D. Hillis ${ }^{2}$ \\ ${ }^{1}$ Epidemic Intelligence Service, Epidemiology Program Office, Centers for Disease Control and \\ Prevention, Atlanta, GA \\ ${ }^{2}$ Division of Reproductive Health, National Center for Chronic Disease Prevention and Health \\ Promotion, Cienters for Disease Control and Prevention, Atlanta, GA \\ ${ }^{3}$ State University of New York, Health Science Center at Brooklyn, Brooklyn, NY
}

\begin{abstract}
The aim of this study was to identify factors ascertainable at initial presentation that predict a complicated clinical course in HIV-negative women hospitalized with pelvic inflammatory disease (PID). We used data from a cross-sectional study of women admitted for clinically diagnosed PID to a public hospital in New York City. A complicated clinical course was defined as undergoing surgery, being readmitted for PID, or having a prolonged hospital stay ( $\geq 14$ days) but no surgery. Logistic regression was used to identify independent predictors of complications. In adjusted analyses, older age ( $\geq 35$ years) was a risk factor for prolonged hospital stay (adjusted odds ratio [OR] = $3.9 ; 95 \%$ confidence interval $[C I]=1.3-11.6)$ and surgery $(\mathrm{OR}=10.4 ; \mathrm{CI}=2.5-44.1)$; self-reported drug use was a risk factor for readmission for $\mathrm{PID}(\mathrm{OR}=7.7$; $\mathrm{CI}=1.4-41.1)$ and surgery $(\mathrm{OR}=$ 6.2; $\mathrm{CI}=1.8-20.5$ ). Older age and self-reported drug use appear to be independent risk factors for a complicated clinical course among women hospitalized with PID. Infect. Dis. Obstet. Gynecol. 8:88-93, 2000. Published 2000 Wiley-Liss, Inc.
\end{abstract}

$P_{n}^{e t r i n g}$ lvic inflammatory disease (PID), which affects nearly 1 in 9 women during their reproductive years, ${ }^{1}$ is associated with serious reproductive health consequences such as infertility, ectopic pregnancy, and chronic pelvic pain., ${ }^{2,3}$ In 1994, PID accounted for approximately 104,000 hospitalizations in the United States (unpublished data, National Hospital Discharge Survey, 1994, National Center for Health Statistics, Centers for Disease Control and Prevention); in the same year, the estimated national costs for this disease were $\$ 4.15$ billion. ${ }^{4}$

Despite common occurrence of PID and high cost to the medical care system, there are still several important unanswered questions about this condition, particularly questions about which women are likely to have a complicated clinical course. As a first step toward determining which women, among all PID patients, are at risk for complications, this study sought to identify risk factors

\footnotetext{
*Correspondence to: Denise Jamieson, M.D., M.P.H., Division of Reproductive Health, Centers for Disease Control and Prevention, Mailstop K34, 4770 Buford Highway N.E., Atlanta, GA 30341. E-mail: djj0@edc.gov

This article is a US government work, and, as such, is in the public domain of the United States of America.
} 
for a complicated course among women hospitalized with PID. Because such factors have not been previously described, this information could contribute to the identifcation of a high-risk group of women for whom outpatient treatment of PID may be inappropriate. For this study, we focused on potential risk factors that can be rapidly identified at initial patient presentation so that these predictors could be useful to the clinician, in an emergency room or clinic setting, in guiding immediate treatment decisions.

\section{SUBJECTS AND METHODS}

This study, which was originally designed to identify the effects of infection with the human immunodeficiency virus (HIV) on the clinical course of PID, was approved by the institutional review board of Kings County Hospital and has been described elsewhere. ${ }^{5}$ Briefly, from July, 1992, to April, 1994, of women admitted to Kings County Hospital with a clinical diagnosis of PID, ${ }^{6} 349$ were found to be eligible for the study. ${ }^{5}$ Twenty-seven of these women were HIV-positive; the present analysis is restricted to the 322 women who were HIV-negative.

Data on demographics, medical history, and clinical course were obtained by medical chart review. In addition, complete blood counts and cervical cultures for $N$. gonorrhoeae and $G$. trachomatis were collected before initiation of treatment. After January, 1993, urine samples were routinely collected at admission or shortly thereafter, according to hospital protocol, for toxicologic studies.

All patients were initially treated with an antibiotic regimen consistent with the 1993 recommendations of the Centers for Disease Control and Prevention. ${ }^{7}$ Criteria for switching antibiotics and surgical intervention for failed therapy, which had been decided upon by the investigators prior to beginning the study, were followed. ${ }^{5}$

For this analysis, we decided that three outcomes would define a complicated clinical course: undergoing surgery during the admission, a hospital stay of $\geq 14$ days but no surgery, and readmission for PID during the study period. Because readmission for PID was considered an outcome measure of interest, if a woman had multiple admissions for PID during the study period, only the first admission was used in the analysis.

Potential predictors for a complicated clinical course included demographic, behavioral, and clinical factors that could be ascertained upon initial patient presentation. To ascertain current drug use, patients were asked if they had used any of the following drugs in the past month: amphetamines, barbituates, benzodiazepines, cannabinoids, cocaine, methadone, opiates, phencyclidine, or any other recreational drugs. Because complete data on demographic and other variables were not available from every chart, the denominators of known responses differ for each variable as indicated in Table 1 . Those variables with $>100$ missing values were not considered potential predictors.

We used the Statistical Analysis Software (SAS Institute Inc., Cary, NC) program to analyze the data. For the univariate analysis, unadjusted odds ratios (ORs) with 95\% confidence intervals (CIs) were calculated to evaluate potential predictors of a complicated clinical course. All variables significant at $P \leq 0.2$ in the univariate analysis were included in the preliminary model for logistic regression. Variables not significant in the preliminary model were eliminated in a stepwise manner. Those variables that resulted in a $\geq 10 \%$ change in the OR of any statistically significant variable were assumed to be confounders and were retained in the final model.

\section{RESULTS}

The mean age of the study population was 27 years; $86.5 \%$ were African American (Table 1). Almost one in every eight women $(11.9 \%)$ reported current drug use, and $22 \%$ had a prior history of PID.

Twenty $(6.2 \%)$ of the 322 women required surgery and 8 others $(2.5 \%)$ were readmitted for PID. All patients who underwent surgery had findings consistent with PID at the time of surgery. Of those women who were readmitted, the time from discharge to readmission ranged from one day to one year, and five of the eight women were readmitted within two days. Of the 302 women who did not undergo surgery, $28(9.3 \%)$ were hospitalized $\geq 14$ days.

Unadjusted analyses (Table 2) showed a significantly increased probability of surgery for older age (>35 years), current self-reported drug use, fever on admission, no current use of birth control, and a below-normal white blood cell count. Prolonged hospitalization was associated with older age and 
TABLE I. Characteristics of HIV-negative women admitted with pelvic inflammatory disease

\begin{tabular}{|c|c|c|c|}
\hline & $N^{a}$ & No. & $\begin{array}{c}\text { Percent } \\
(\%) \\
\end{array}$ \\
\hline \multicolumn{4}{|l|}{ Demographics } \\
\hline Age $(y)$ & 321 & & \\
\hline$<24$ & & $14 \mid$ & 43.9 \\
\hline $25-34$ & & 123 & 38.3 \\
\hline$\geq 35$ & & 57 & 17.8 \\
\hline Race/ethnicity & 318 & & \\
\hline African American & & 275 & 86.5 \\
\hline Hispanic & & 18 & 5.6 \\
\hline Carribean American & & 20 & 6.3 \\
\hline White & & 0 & 0.0 \\
\hline Other & & 5 & 1.6 \\
\hline \multicolumn{4}{|l|}{ Behavioral risk factors } \\
\hline Sexual partners, lifetime & 260 & & \\
\hline$<10$ & & 231 & 88.8 \\
\hline$\geq 10$ & & 29 & 11.2 \\
\hline Current self-reported drug use & 320 & & \\
\hline No & & 282 & 88.1 \\
\hline Yes & & 38 & 11.9 \\
\hline Current use of birth control & 312 & & \\
\hline No & & 167 & 53.5 \\
\hline Yes & & 145 & 46.5 \\
\hline Current smoker & 316 & & \\
\hline No & & 209 & 66.1 \\
\hline Yes & & 107 & 33.9 \\
\hline \multicolumn{4}{|l|}{ Past medical history } \\
\hline Prior ectopic pregnancy & 306 & & \\
\hline No & & 284 & 92.8 \\
\hline Yes & & 22 & 7.2 \\
\hline Prior PID & 318 & & \\
\hline No & & 248 & 78.0 \\
\hline Yes & & 70 & 22.0 \\
\hline History of $N$. gonorrhoeae & 318 & & \\
\hline No & & 293 & 92.1 \\
\hline Yes & & 25 & 7.9 \\
\hline History of C. trachomatis & 318 & & \\
\hline No & & 304 & 95.6 \\
\hline Yes & & 14 & 4.4 \\
\hline History of Trichomonas & 318 & & \\
\hline No & & 307 & 96.5 \\
\hline Yes & & 11 & 3.5 \\
\hline \multicolumn{4}{|l|}{ Presenting signs/symptoms } \\
\hline \multicolumn{4}{|l|}{ Duration of presenting } \\
\hline symptoms before admission (days) & 295 & & \\
\hline$<4$ days & & 127 & 43.1 \\
\hline$\geq 4$ days & & 168 & 56.9 \\
\hline Admission fever $(>100.4 \mathrm{~N} \mathrm{~F})$ & 308 & & \\
\hline No & & 209 & 67.9 \\
\hline Yes & & 99 & 32.1 \\
\hline \multicolumn{4}{|l|}{ Laboratory data at admission ${ }^{\mathrm{b}}$} \\
\hline White blood count $\left(\times 10^{9} / \mathrm{L}\right)$ & 316 & & \\
\hline$<4.8$ & & 17 & 5.4 \\
\hline $4.8-10.8$ & & 162 & 51.3 \\
\hline$>10.8$ & & 137 & 43.3 \\
\hline
\end{tabular}

${ }^{\mathrm{a}} \mathrm{N}$ varies by characteristic because of missing data. 'Normal laboratory values: white blood cell count $4.8-10.8 \times 10^{9}$ per liter. fever on admission. In contrast, current smoking was negatively associated with prolonged hospitalization. Significant risk factors for readmission were a lifetime number of sexual partners of ten or more, current self-reported drug use, and a history of trichomoniasis. Potential risk factors not shown in Table 2 that were not found to be significantly associated with any of the three measures of poor clinical course included race; age at first intercourse; current use of oral contraceptives; current use of an intrauterine device; prior history of ectopic pregnancy, PID, gonorrhea, chlamydia, or syphilis; presenting with symptoms of chills, diarrhea, nausea, vaginal spotting, or discharge; duration of presenting symptoms prior to admission; presenting signs of rebound, vaginal discharge, or adnexal mass noted on physical exam; and anemia on admission.

We also considered two potential risk factors that cannot be evaluated on initial presentation but that might be expected to predict outcome: positive $N$. gonorrhoeae or $C$. trachomatis cervical cultures. In unadjusted analyses, results for these cultures did not predict any of the three outcome measures (Table 3).

In adjusted analyses (Table 4), older age (>35 years) remained a risk factor for surgery and prolonged hospitalization and self-reported current drug use remained a risk factor for surgery and readmission. Because older age and self-reported drug use were predictors for poor outcome, we looked more closely at whether the presence of a tubo-ovarian abscess, diagnosed either on ultrasound or at the time of surgery, could help explain these findings. Although older women were not more likely to have a tubo-ovarian abscess $(\mathrm{OR}=$ 1.8; CI =0.9-3.4), women reporting drug use were more likely to have a diagnosis of tubo-ovarian abscess $(\mathrm{OR}=2.6 ; \mathrm{CI}=1.2-5.7)$.

Because self-reported drug use remained a significant risk factor for two out of the three criteria for a complicated clinical course, we examined this relationship more closely by evaluating data from urine toxicology screens. Since urine toxicology screens were not routinely done until approximately halfway through the study period, only 207/ $322(64 \%)$ of women had toxicology results available. The following substances were screened for in the urine: amphetamines, barbituates, benzodiazepines, cannabinoids, cocaine and its metabo- 
TABLE 2. Unadjusted odds ratios ${ }^{\mathrm{a}}$ for complicated course by potential predictors among HIV-negative women with clinically diagnosed pelvic inflammatory disease

\begin{tabular}{|c|c|c|c|}
\hline Potential predictor & Surgery & $\begin{array}{c}\text { Prolonged } \\
\text { hospitalization } \\
(\geq 14 \text { days })^{\mathrm{b}}\end{array}$ & $\begin{array}{l}\text { Readmission } \\
\text { for PID } \\
\end{array}$ \\
\hline \multicolumn{4}{|l|}{ Demographics } \\
\hline \multicolumn{4}{|l|}{ Age $(y)$} \\
\hline$\leq 24$ & Referent & Referent & Referent \\
\hline $25-34$ & $0.7(0.3-1.8)$ & $1.4(0.6-3.1)$ & $2.7(0.7-11.1)$ \\
\hline$\geq 35$ & $6.8(3.0-15.6)$ & $2.5(1.0-5.9)$ & $0.7(0.1-5.4)$ \\
\hline \multicolumn{4}{|l|}{ Behavioral risk factors } \\
\hline \multicolumn{4}{|c|}{ Sexual partners, lifetime } \\
\hline$<10$ & Referent & Referent & Referent \\
\hline$\geq 10$ & $1.3(0.3-6.4)$ & $1.2(0.3-4.3)$ & $6.5(1.7-25.7)$ \\
\hline \multicolumn{4}{|c|}{ Current self-reported drug use } \\
\hline No & Referent & Referent & Referent \\
\hline Yes & $4.7(1.9-11.7)$ & I.I (0.3-3.9) & $8.2(2.4-27.8)$ \\
\hline \multicolumn{4}{|c|}{ Current use of birth control } \\
\hline No & $2.8(1.0-7.5)$ & $1.7(0.8-3.9)$ & $0.5(0.1-2.1)$ \\
\hline Yes & Referent & Referent & Referent \\
\hline \multicolumn{4}{|l|}{ Current smoker } \\
\hline No & Referent & Referent & Referent \\
\hline Yes & $1.3(0.5-3.4)$ & $0.3(0.1-0.9)$ & $1.2(0.3-5.0)$ \\
\hline \multicolumn{4}{|l|}{ Past medical history } \\
\hline \multicolumn{4}{|c|}{ Prior ectopic pregnancy } \\
\hline No & Referent & Referent & Referent \\
\hline Yes & $0.8(0.1-6.3)$ & $2.8(0.9-8.6)$ & $0.9(0.1-17.4)$ \\
\hline \multicolumn{4}{|l|}{ Prior PID } \\
\hline No & Referent & Referent & Referent \\
\hline Yes & $1.6(0.6-4.2)$ & $0.8(0.3-2.1)$ & $1.2(0.2-6.0)$ \\
\hline \multicolumn{4}{|c|}{ History of $N$. gonorrhoeae } \\
\hline No & Referent & Referent & Referent \\
\hline Yes & $0.6(0.1-4.6)$ & $1.4(0.4-5.1)$ & $4.2(0.9-19.3)$ \\
\hline \multicolumn{4}{|c|}{ History of C. trachomatis } \\
\hline No & Referent & Referent & Referent \\
\hline Yes & $0.5(0-8.3)$ & $1.7(0.4-7.7)$ & $1.2(0.1-21.9)$ \\
\hline \multicolumn{4}{|c|}{ History of Trichomonas } \\
\hline No & Referent & Referent & Referent \\
\hline Yes & $0.6(0-10.7)$ & $0.4(0-6.9)$ & II.I (2.7-45.3) \\
\hline \multicolumn{4}{|c|}{ Presenting signs \& symptoms } \\
\hline \multicolumn{4}{|c|}{ Duration of presenting symptoms before admission (days) } \\
\hline$<4$ & Referent & Referent & Referent \\
\hline$\geq 4$ & $1.4(0.4-4.2)$ & $1.2(0.5-2.7)$ & $0.8(0.2-3.8)$ \\
\hline \multicolumn{4}{|c|}{ Admission fever $\left(>100.4^{\circ} \mathrm{F}\right)$} \\
\hline No & Referent & Referent & Referent \\
\hline Yes & $3.1(1.3-7.8)$ & $2.3(1.1-5.1)$ & $0.1(0-2.1)$ \\
\hline \multicolumn{4}{|c|}{ Laboratory data at admission ${ }^{c}$} \\
\hline \multicolumn{4}{|c|}{ White blood count cell $\left(\times 10^{9} / \mathrm{L}\right)$} \\
\hline$<4.8$ & $4.7(1.2-18.2)$ & $0.9(0.1-7.7)$ & $1.6(0.2-14.2)$ \\
\hline $4.8-10.8$ & Referent & Referent & Referent \\
\hline$>10.8$ & $1.6(0.6-4.3)$ & $1.5(0.7-3.3)$ & $0.2(0-1.3)$ \\
\hline
\end{tabular}

${ }^{a}$ With $95 \%$ confidence intervals.

${ }^{\text {bNo surgery. }}$

'Normal laboratory values: white blood count $4.8-10.8 \times 10^{9}$ per liter.

lites, methadone, opiates, and phencyclidine. We found that $22.2 \%$ of the women tested had positive toxicology screens; we also found that $16.0 \%$ of those who denied drug use had positive toxicology screens, and $34.6 \%$ of those who reported current drug use had negative toxicology screens (data not shown). Toxicology results alone did not predict any of the three outcome measures. We also found that when drug use was defined as either a positive toxicology screen or self-reported use, the ORs did 
TABLE 3. Unadjusted odds ratios ${ }^{\mathrm{a}}$ for complicated clinical course by $N$. gonorrhoeae and $C$. trachomatis cervical culture among HIV-negative women with clinically diagnosed pelvic inflammatory disease

\begin{tabular}{|c|c|c|c|c|c|c|}
\hline & $\mathrm{N}$ & No. & $\%$ & Surgery & $\begin{array}{c}\text { Prolonged } \\
\text { hospitalization } \\
(\geq 14 \text { days })^{\mathrm{b}}\end{array}$ & $\begin{array}{c}\text { Readmission } \\
\text { for PID }\end{array}$ \\
\hline N. gonorrhoeae culture & 258 & & & & & \\
\hline Positive & & 43 & 16.7 & $0.3(0-1.9)$ & $0.9(0.3-2.7)$ & $0.3(0-5.7)$ \\
\hline Negative & & 215 & 83.3 & Referent & Referent & Referent \\
\hline C. trachomatis culture & 224 & & & & & \\
\hline Positive & & 33 & 14.7 & $0.3(0-4.5)$ & $0.8(0.2-2.9)$ & $6.1(0.8-44.9)$ \\
\hline Negative & & 191 & 85.3 & Referent & Referent & Referent \\
\hline
\end{tabular}

aWith $95 \%$ confidence intervals.

bNo surgery.

TABLE 4. Adjusted odds ratios ${ }^{\mathrm{a}}$ for complicated clinical course among HIV-negative women with clinically diagnosed pelvic inflammatory disease

\begin{tabular}{lccc}
\hline Potential predictor & Surgery & $\begin{array}{c}\text { Prolonged } \\
\text { hospitalization } \\
(\geq 14 \text { days })^{\mathrm{b}}\end{array}$ & $\begin{array}{c}\text { Readmission } \\
\text { for PID }\end{array}$ \\
\hline Age $25-34$ y & $1.7(0.4-7.6)$ & $2.3(0.9-6.1)$ & $3.9(1.3-11.6)$ \\
Age $\geq 35$ y & $10.4(2.5-44.1)$ & & $7.7(1.4-41.1)$ \\
Self-reported current drug use & $6.2(1.9-20.5)$ & & $3.1(0.6-17.3)$ \\
$\geq 10$ sexual partners (lifetime) & $2.7(0.8-8.9)$ & & \\
No current birth control method & $1.9(0.7-5.4)$ & & \\
Admission fever & & & \\
\hline
\end{tabular}

aWith $95 \%$ confidence intervals; adjustment using logistic regression.

${ }^{\text {bNo surgery. }}$

not change appreciably from those obtained when use was defined simply from self-report.

\section{DISCUSSION}

Our analysis of HIV-negative women admitted with PID to a large, public, urban hospital suggest that older women ( $\geq 35$ years) and those who use drugs may have an elevated risk of a complicated clinical course. Whether these findings might be applied to the decision-making process about PID in the outpatient setting is uncertain and should not be presumed; a study of the relationship between older age and drug use and the success of outpatient therapy would be of interest. We also found in this study that even though drug use was associated with a complicated clinical course, a positive urine toxicology screen was not. In addition, we found that results from $N$. gonorrhoeae and C. trachomatis cervical cultures were not found to be predictive of a complicated clinical course.

Our finding that older women with PID may be at relatively greater risk for surgery and prolonged hospitalization complements an earlier finding that older women are at higher risk for long-term sequelae of PID, such as infertility. ${ }^{8}$ Our finding that current drug use may be a risk factor for surgery and readmission might reflect poorer overall health of drug users or other factors that our study did not address, such as access to health care and other health behaviors.

Several limitations of this study should be noted. First, as in most U.S. studies of PID, diagnosis was made from clinical criteria and not from laparoscopy. Several studies have found that 45$65 \%$ of cases diagnosed as PID by clinical criteria were not confirmed by laparoscopy. ${ }^{9,10}$ Second, our study population was urban and largely African American; whether our results can be generalized to other populations is unclear. Third, the extent to which our findings may be relevant to the outpatient setting is unknown because we confined our study to inpatients. Fourth, readmission for PID during the study period may either represent an initial treatment failure or may represent reinfec- 
tion. Because five of the eight women were readmitted within two days of discharge, it seems plausible that at least some of these readmissions represent treatment failures. Finally, our small sample size may have limited our power to detect significant differences for some of the risk factors considered.

In conclusion, PID remains an important and costly clinical problem. In the modern health-care environment, there is considerable pressure to treat this disease as well as many other inféctious disorders on an outpatient basis whenever possible. Furthermore, when women are hospitalized with PID, pressures are often exerted to minimize their hospital stay in a way that does not compromise excellent clinical care. The present study may be an early step in determining the factors that predispose women with PID to a difficult clinical course, and this information may influence decisionmaking about resource use for this illness.

\section{REFERENCES}

1. Aral SO, Mosher WD, Cates W. Self-reported pelvic inflammatory disease in the United States, 1988. JAMA 1991;266:2570-2573.

2. Buchan H, Vessey M, Goldacre M, Fairweather J. Morbidity following pelvic inflammatory disease. $\mathrm{Br} \mathrm{J} \mathrm{Ob-}$ stet Gynaecol 1993;100:558-562.
3. Westrom L, Joesoef R, Reynolds G, Hagdu A, Thompson SE. Pelvic inflammatory disease and fertility: a cohort study of 1,844 women with laparoscopically verified disease and 657 control women with normal laparoscopic results. Sex Transm Dis 1992;19:185-192.

4. Eng TR, Butler WT, editors. The Hidden Epidemic: Confronting Sexually Transmitted Diseases. Washington D.C.: National Academy Press; 1997. 59 p.

5. Barbosa G, Macasaet M, Brockmann S, Sierra MF, Xia $Z$, Duerr A. Pelvic inflammatory disease and human immunodeficiency virus infection. Obstet Gynecol 1997;89:65-70.

6. Hager WD, Eschenbach DA, Spence MR, Sweet RL. Criteria for diagnosis and grading of salpingitis. Obstet Gynecol 1983;61:113-114.

7. Centers for Disease Control and Prevention. 1993 sexually transmitted disease treatment guidelines. MMWR 1993;42:1-102.

8. Westrom L. Incidence, prevalence, and trends of acute pelvic inflammatory disease and its consequences in industrialized countries. Am J Obstet Gynecol 1980;138: 880-892.

9. Jacobson L, Westrom L. Objectivized diagnosis of acute pelvic inflammatory disease: diagnostic and prognostic value of routine laparoscopy. Am J Obstet Gynecol 1969;105:1088-1098.

10. Chaparro MV, Ghosh S, Nashed A, Poliak A. Laparoscopy for the confirmation and prognostic evaluation of pelvic inflammatory disease. Int J Gynaecol Obstet 1978;15:307-309. 


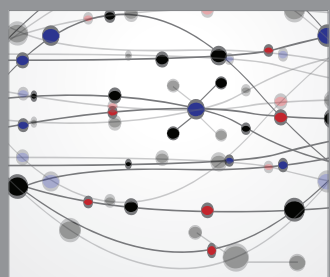

The Scientific World Journal
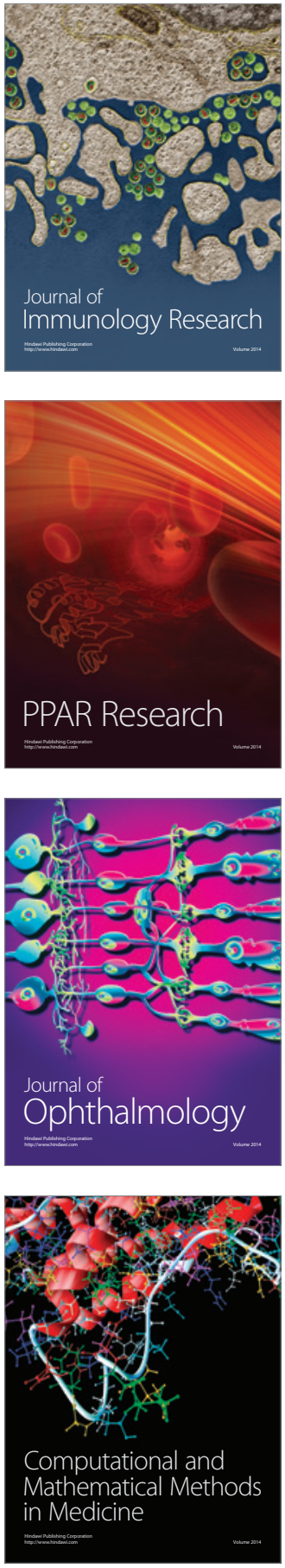

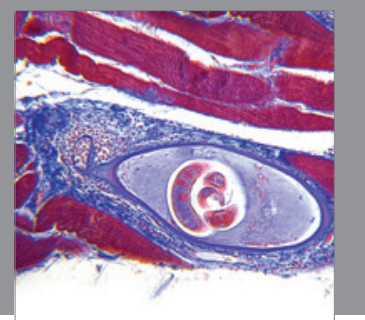

Gastroenterology

Research and Practice
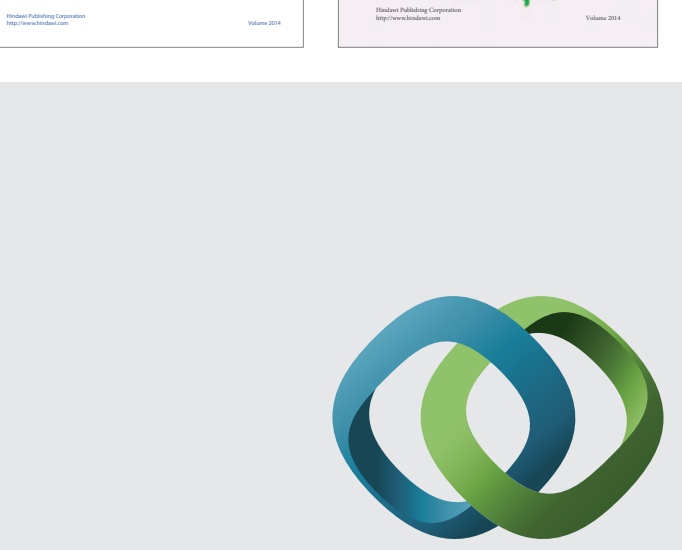

\section{Hindawi}

Submit your manuscripts at

http://www.hindawi.com
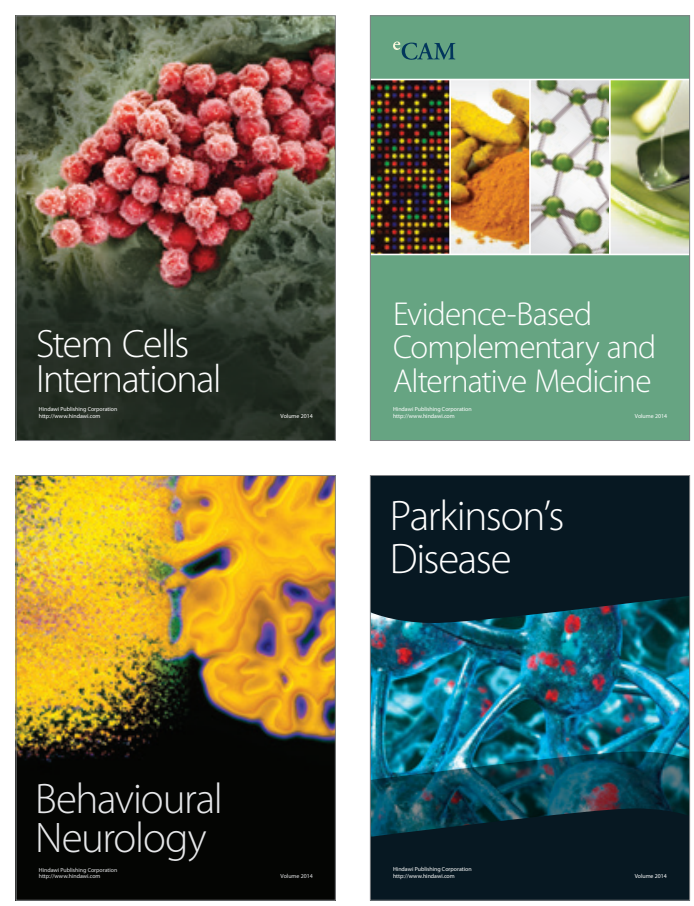

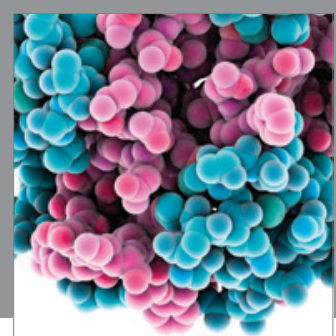

Journal of
Diabetes Research

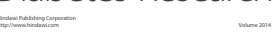

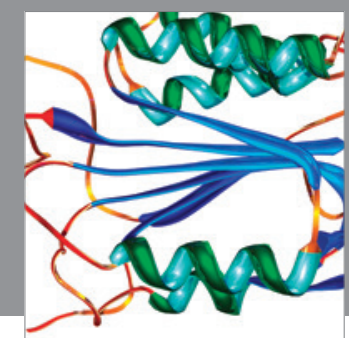

Disease Markers
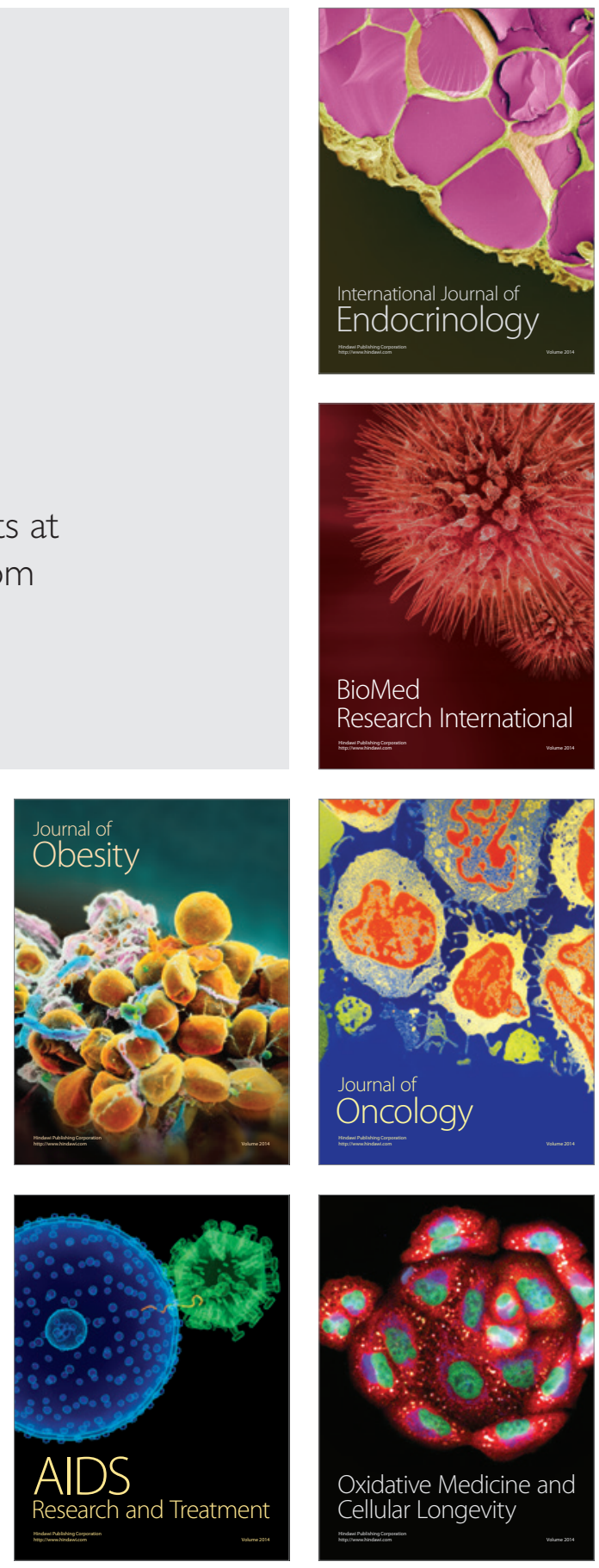